\title{
Equilibrium, Adsorption Isotherm and Kinetic Studies on the Removal of Methylene Blue Dye from Aqueous Solution onto Senna Occidentalis Seeds Activated Carbon
}

\author{
Gulumbe, N.S. ${ }^{1^{*}} \quad$ Bello, K.A. ${ }^{1} \quad$ Yakubu, M.K. $^{1} \quad$ Abdulazeez, A.Y. ${ }^{2}$ \\ 1.Department of Polymer and Textile Engineering, Faculty of Engineering, Ahmadu Bello University, Zaria - \\ Nigeria \\ 2.Department of Textile Technology, Collage of Science \& Technology, Kaduna Polytechnic, Kaduna State - \\ Nigeria
}

\begin{abstract}
This paper studied the adsorption potentials and efficiency of low cost activated carbon produced from Senna occidentalis seeds for the removal of Methylene Blue dye in aqueous solutions. Batch adsorption experiments were carried out to investigate the effects of variables such as initial dye concentration, carbon dosage, contact time, $\mathrm{pH}$ and temperature to the process. Similarly, adsorption isotherms consisting Langmuir, Freundlich and Temkin were employed and found Langmuir Adsorption model fitted best. However, Kinetic models consisting pseudo first-order, pseudo second-order and intra-particle diffusion were also used to investigate the kinetic nature of the process, and found that pseudo second-order model better explained the process.
\end{abstract}

Keywords: Equilibrium, Adsorption Isotherm, Kinetic Studies, Activated Carbon and Methylene Blue Dye

DOI: $10.7176 / \mathrm{CMR} / 11-4-04$

Publication date: April $30^{\text {th }} 2019$

\section{Introduction}

The environmental and health issues associated with residual colour (which is basically due to dyes and pigments) in textile effluents have posed a major challenge to environmental scientists as well as the textile colouration processors (Joshi et al., 2004).

Large scale production and the widespread application of synthetic dyes by various industries such as the textile, leather, tanning, food, cosmetics, paper printing, plastics etc. lead to severe contamination of surface and groundwater sources in the vicinity of dye industries (Ali et al., 2010).

Synthetic dyes often have complex aromatic molecular structures that make them more difficult to naturally biodegrade. However, their disposal in water bodies exhibit adverse effect to the aquatic and human life by creating eutrophication mutagenic, carcinogenic effects, dysfunction of the organs, also having effect on aquatic ecosystem by preventing sunlight from reaching into the water bodies (Sharifi et al., 2018).

Some of the available methods for dyes removal or degradation include; aerobic biodegradation (Liu et al., 2018), membrane nano-filtration (Oatley-Radcliffe et al., 2017), photocatalytic degradation (Giwa et al., 2016), adsorption (Okoli et al., 2015), electro-coagulation (Nandi and Patel, 2013), ozonation (Wijannarong et. al., 2013), precipitation (Gupta et. al., 2012), electrochemical (Jain et al., 2004) etc.

Many studies have been undertaken for the removal of pollutants by using variety of materials (used as adsorbents) ranging from agricultural waste or agro-by-products such as; coir pith (Namasivayam and Kavitha, 2002), date seeds (Yakubu et al., 2008), rice husk (Sharma and Janveja, 2008), mango seed shell (Akpen et al., 2011), groundnut shell (Mohammed et al., 2015), tamarind seed (Okoli et al., 2015), aloe vera leaves shell (Omidi et al., 2017); biomass such as cellulose dust (Sharifi et al., 2018) to varieties of clays (Vimonsesa et al., 2009).

Activated carbon is extensively used as an adsorbent due to its high level of effectiveness, but it is expensive and has high usage costs. This has motivated many environmental scientists to embark on exploration for inexpensive and locally available adsorbents so that the process can become economically viable. In this study, the use of Senna Occidentalis Seeds Activated Carbon (SOSAC) as an adsorbent for the removal of a MB dye from aqueous solution was carried out. Senna occidentalis is a cheaply available plant occurring as shrub that is regarded as weed or not important. The plant is said to be found throughout Nigeria (especially in the northern part) along major highways, growing abundantly on waste lands (Gulumbe et al. 2019).

\section{Materials and Methods}

The major materials used in this study are; Senna occidentalis seeds which was obtained from Birnin Kebbi local government area of Kebbi State, Nigeria, from which the adsorbent was prepared; Methylene blue dye which was purchased from Cardinal Scientific Supplies, Zaria, Nigeria, from which the adsorbate solution was prepared. Other materials used include zinc chloride, hydrochloric acid, sodium hydroxide, double-distilled water etc. All other chemicals used were of analytical reagent grade. 


\subsection{Preparation of Adsorbent}

The adsorbent used in this study was adopted from the already prepared SOSAC with its preparatory methods been reported in the earlier work (Gulumbe et al., 2019). The intention of this research is to evaluate and confirm the adsorption potentials of SOSAC as reported in the earlier research.

\subsection{Preparation of Adsorbate}

Methylene blue (MB) dye of commercial-grade purchased from Cardinal Scientific Supplies was used as received to prepare a stock solution. This is done by dissolving $1 \mathrm{~g}$ of the powdered MB dye into 1 litre of distilled water to obtain stock solution of $1 \mathrm{~g} / \mathrm{L}$ concentration. The following specifications concerning the dye were obtained before use: Name - Basic Blue 9, C.I No. - 52015, chemical formula $-\mathrm{C}_{16} \mathrm{H}_{18} \mathrm{ClN}_{3} \mathrm{~S}$, molecular weight $-319.85 \mathrm{~g} / \mathrm{mol}$ and $\lambda \max -670 \mathrm{~nm}$.

However, the experimental solutions in the desired concentrations were prepared through subsequent dilutions of the stock solution.

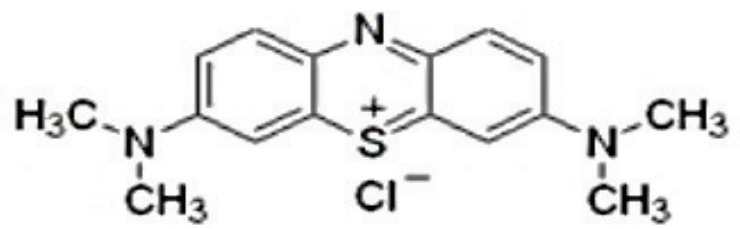

Figure 1: Chemical Structure of Methylene Blue Dye

\subsection{Equilibrium Adsorption Studies}

Batch adsorption process was employed in these studies, and in each adsorption process, $100 \mathrm{ml}$ of dye solution with a known concentration (in $\mathrm{mg} / \mathrm{L}$ ) was added to a mass (in $\mathrm{g}$ ) of activated carbon in a $250 \mathrm{ml}$ clean beaker at a room temperature (of about $30{ }^{\circ} \mathrm{C}$ ), and the mixture was stirred on a magnetic stirrer at $100 \mathrm{rpm}$. The samples were withdrawn from stirring setup at a predetermined time intervals, allowed to settle for 10-15 minutes and the adsorbent was separated from the solution by the help of a micropipette. The absorbance of the supernatant solution was estimated to determine the residual dye concentration, and was measured before and after treatment with the help of spectrophotometer at the maximum wavelength of $670 \mathrm{~nm}$.

The adsorption parameters varied include; initial MB dye concentration (10-60) mg/L; contact time (20180) minutes; $\mathrm{pH}(3-11)$; temperature at $(303,313$ and 323) $\mathrm{K}$ and carbon dosage (0.5-2.5) $\mathrm{g}$. The $\mathrm{pH}$ of the dye solution was adjusted by using $0.1 \mathrm{M} \mathrm{NaOH}$ or $0.1 \mathrm{M} \mathrm{HCl}$ solution and a $\mathrm{pH}$ meter.

The parameters variation was to determine their effects to the equilibrium adsorption, the adsorption isotherm as well as kinetics of MB dye adsorption onto SOSAC.

The amount of $\mathrm{MB}$ dye adsorbed at time, $\mathrm{t}, \mathrm{q}_{\mathrm{t}}(\mathrm{mg} / \mathrm{g})$ as well as the percentage dye removed (\%) were calculated using the eq. 1 and 2 respectively:

$$
\begin{aligned}
& \mathrm{q}_{\mathrm{t}}=\frac{\left(C_{0}-C t\right) \times V}{M} \\
& \mathrm{R}(\%)=\frac{\left(C_{0}-C \theta\right)}{C_{\mathrm{n}}} \times 100
\end{aligned}
$$

where; $\mathrm{C}_{0}$ and $\mathrm{C}_{\mathrm{t}}$ are the initial concentration of the dye in solution $(\mathrm{mg} / \mathrm{L})$ and equilibrium concentrations of the dye in solution at time, $\mathrm{t}(\mathrm{mg} / \mathrm{L}), \mathrm{V}$ is the volume of the solution used $(\mathrm{L})$ and $\mathrm{M}$ is the mass of the adsorbent $(\mathrm{g})$.

\subsection{Adsorption Isotherms}

There are several isotherm equations available for analysing experimental adsorption equilibrium parameters and the most common being the Langmuir, Freundlich and Temkin models. Meanwhile, the mathematical relationship between the amount of $M B$ dye adsorbed $\left(q_{t}\right)$ and its equilibrium concentration at time, $t\left(C_{t}\right)$, was evaluated using Langmuir, Freundlich and Temkin adsorption isotherms.

\subsubsection{Langmuir Adsorption Isotherm}

The Langmuir isotherm model is based on the assumption that there is a finite number of active sites which are homogeneously distributed over the surface of the adsorbent These active sites have the same affinity for adsorption of a mono molecular layer and without interaction between the adsorbed molecules.

The Linear form of the Langmuir equation can be expressed as eq. 3 (Langmuir, 1916; Langmuir, 1918):

$\mathrm{C}_{\mathrm{t}} / \mathrm{q}_{\mathrm{t}}=1 / \mathrm{K}_{\mathrm{L}} q_{m}+1 / q_{m} \times \mathrm{C}_{\mathrm{t}}$

where; $\mathrm{q}_{\mathrm{t}}$ is the amount of dye adsorbed $(\mathrm{mg} / \mathrm{g}), \mathrm{C}_{\mathrm{t}}$ is the equilibrium concentration of the adsorbate at time, $\mathrm{t}(\mathrm{mg} / \mathrm{L})$, while $\mathrm{q}_{\mathrm{m}}$ and $\mathrm{K}_{\mathrm{L}}$ are Langmuir constants that stand for maximum adsorption capacity (mg/g) and energy of adsorption $(\mathrm{L} / \mathrm{mg})$. When adsorption obeys the Langmuir equation, a plot of $\mathrm{C}_{t} / \mathrm{q}_{t}$ against $\mathrm{C}_{t}$ should give a straight line graph with a slope of $1 / \mathrm{qm}$ and intercept of $1 / \mathrm{K}_{\mathrm{L}} \times \mathrm{q}_{\mathrm{m}}$.

However, another very important characteristic of Langmuir isotherm is called Langmuir Dimensionless Separation Factor $\left(R_{L}\right)$ which can be obtained from the eq. 4: 


$$
\mathrm{R}_{\mathrm{L}}=1 /\left(1+\mathrm{K}_{\mathrm{L}} \mathrm{C}_{0}\right)
$$

where; $\mathrm{C}_{0}$ is the highest initial dye concentration $(\mathrm{mg} / \mathrm{L})$

The $R_{L}$ value normally indicates the type of adsorption either it is favourable (i.e. $0<R_{L}<1$ ), unfavourable (i.e. $\mathrm{R}_{\mathrm{L}}>1$ ), feasible or linear (i.e. $\mathrm{R}_{\mathrm{L}}=1$ ) or irreversible (i.e. $\mathrm{R}_{\mathrm{L}}=0$ ).

2.4.2 Freundlich Adsorption Isotherm

The Freundlich isotherm model is the earliest known relationship describing the non-ideal and reversible adsorption, which can be applied to multilayer adsorption, on the basis of an assumption concerning the energetic surface heterogeneity. The Freundlich model is an empirical equation based on the distribution of solute between the solid phase and aqueous phase at equilibrium. The Freundlich model is used for heterogeneous surfaces but can describe adsorption data over a restricted range only ( $\mathrm{Ng}$ et. al., 2002).

The linear form of Freundlich equation can be expressed as eq. 5 (Freundlich, 1906):

$$
\ln \mathrm{q}_{\mathrm{t}}=\ln \mathrm{K}_{\mathrm{f}}+1 / \mathrm{n} \ln \mathrm{C}_{\mathrm{t}}
$$

where; $\mathrm{q}_{\mathrm{t}}$ is the amount of dye adsorbed at any time $(\mathrm{mg} / \mathrm{g}), \mathrm{C}_{\mathrm{t}}$ is the equilibrium concentration at any time $(\mathrm{mg} / \mathrm{L}), \mathrm{K}_{\mathrm{f}}$ and $\mathrm{n}$ are Freundlich constants related to maximum adsorption capacity $(\mathrm{mg} / \mathrm{g})$ and surface heterogeneity (dimensionless). The values of $\mathrm{K}_{\mathrm{f}}$ and $1 / \mathrm{n}$ can be obtained respectively from intercept and slope of plot of the $\ln \mathrm{q}_{\mathrm{t}}$ against $\ln \mathrm{C}_{\mathrm{t}}$.

\subsubsection{Temkin Adsorption Isotherm}

Temkin adsorption model assumes that the fall in the heat of sorption is linear rather than logarithmic, as implied in the Freundlich equation. The appropriate isotherm according to Temkin is shown in the eq. 6 (Tempkin and Pyzhev, 1940):

$$
\begin{aligned}
& \mathrm{q}_{\mathrm{e}}=(\mathrm{RT}) / \mathrm{b}_{\mathrm{T}} \ln \mathrm{k}_{\mathrm{T}}+(\mathrm{RT}) / \mathrm{b}_{\mathrm{T}} \ln \mathrm{C}_{\mathrm{e}} \\
& \mathrm{B}_{1}=\mathrm{RT} / \mathrm{b}_{\mathrm{T}}
\end{aligned}
$$

where; $b_{\mathrm{T}}$ indicates the adsorption potential of the adsorbent, $\mathrm{k}_{\mathrm{T}}$ is the equilibrium binding constant $(\mathrm{L} / \mathrm{mg})$ and $\mathrm{B}_{1}$ is the Temkin heat of sorption $(\mathrm{J} / \mathrm{mol})$ which can be obtained from eq. 7 .

\section{Results and Discussion}

\subsection{Effect of Initial MB Dye Concentration}

The result for the effect of initial concentration of $\mathrm{MB}$ dye to its removal onto the activated carbon was presented in Fig. 2. The concentration of MB solution was varied from the ranges of $10-60 \mathrm{mg} / \mathrm{L}$ at $1.5 \mathrm{~g} / 100 \mathrm{~mL}$ carbon dosage and solution $\mathrm{pH}$ of 7.3. It can be seen from Fig. 2 that percentage MB dye removal increased with increased in initial adsorbate concentration, and similar was reported by other researchers (Akpen et. al., 2011). The highest removal recorded was at $93.6 \%$.

\section{Effect of Concentration on Dye Removal Efificiency}

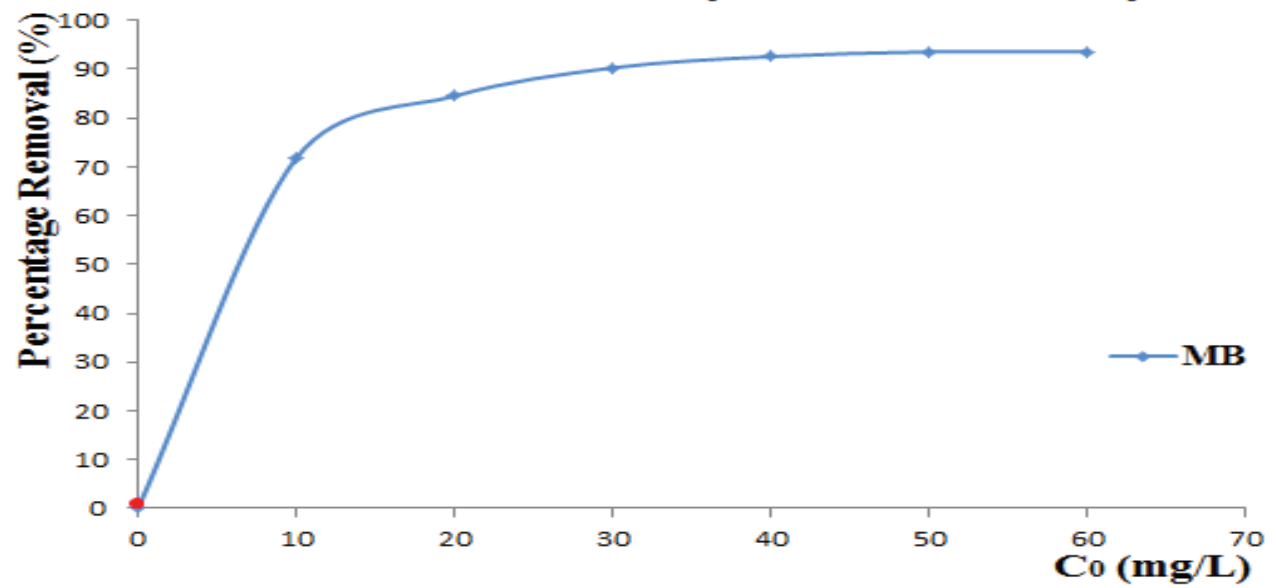

Fig. 2: Effect of Initial Dye Concentration on the Percentage MB Dye Removal onto SOSAC at 1.5g Carbon Dose and Contact Time of 60 minutes.

\subsection{Effect of Contact Time}

The result for the effect of contact time is presented in Fig. 3 which clearly shows the extent of adsorption is rapid in the initial stage and becomes slow in later stage till saturation was reached. It is chiefly because of the saturation of the active sites on the SOSAC, which do not permit furthermore adsorption to occur. This can be explained by the fact that initially, the quantity of sites on the surface is very large which allows adsorption to take place very easily. But with the passage of time, the active sites get saturated thereby reducing the rate at which adsorption occurred. 


\section{Effect of Contact Time on Dye Removal Efficiency}

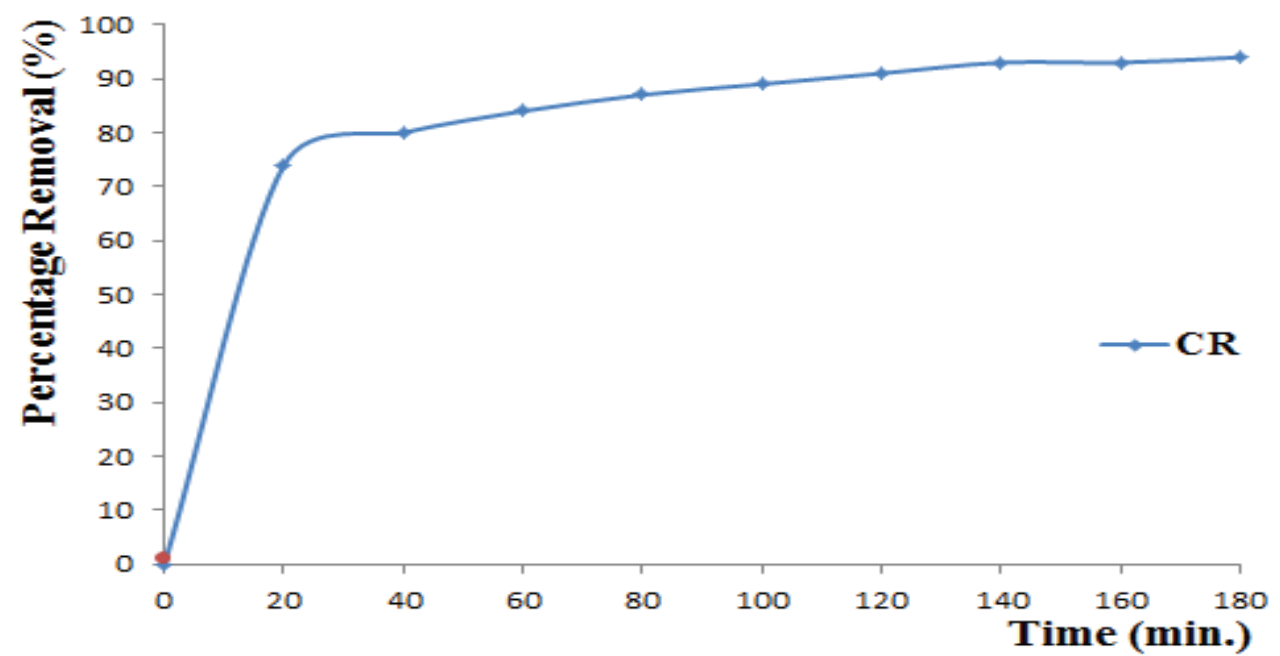

Fig. 3: Effect of Contact Time on the Percentage MB Dye Removal onto SOSAC at $2 \mathrm{~g}$ Carbon Dose and 50 $\mathrm{mg} / \mathrm{L}$ Dye Concentration.

\subsection{Effect of SOSAC Dosage}

The result for variation of percentage removal of $\mathrm{MB}$ with adsorbent doses of $0.5,1,1.5,2$ and $2.5 \mathrm{~g}$ at dye concentration of $50 \mathrm{mg} / \mathrm{L}$ is presented in Fig.4. The figure revealed that an increase in the quantity of SOSAC results in a corresponding increase in the amount of $\mathrm{MB}$ dye removed. This increase in removal efficiency with simultaneous increase in adsorbent dose is due to the increase in surface area and hence more sites were available for adsorption of the dye. Similarly, it is clear that the SOSAC has achieved at least 93\% removal of $\mathrm{MB}$ dye from the aqueous solution. However, $1 \mathrm{~g} / 100 \mathrm{ml}$ of SOSAC was chosen to be the optimum carbon dose under this study. This finding is in line with the result that has been reported (Akpen et. al., 2011).

\section{Effect of SoS AC Dose on Dye Removal Efficiency}



Fig. 4: Effect of Adsorbent Dosage on the Percentage MB Dye Removal onto SOSAC at 50 mg/L Dye Concentration and 60 minutes Contact time.

\subsection{Effect of Initial $p H$}

The effect of initial $\mathrm{pH}$ on dye solution for the MB dye removal was investigated by varying the $\mathrm{pH}$ from 3 to 11 and presented in the Fig. 5. SOSAC has achieved maximum removal of $\mathrm{MB}$ dye at $\mathrm{pH}=11$ and decreased down the $\mathrm{pH}$ Scale as we see in Fig 5. In fact adsorption was found to increase with increase in $\mathrm{pH}$ of solution. The adsorption of these positively charged dye groups on the adsorbent surface is primarily influenced by the surface charge on the adsorbent which in turn is influenced by the solution $\mathrm{pH}$. The result showed that availability of negatively charged groups at the adsorbent surface is necessary for the adsorption of basic dyes to proceed which we see at $\mathrm{pH}-3$ is almost minimum as there is a net positive charge in the adsorption system due to the presence of $\mathrm{H}_{3} \mathrm{O}^{+}$. Thus as the $\mathrm{pH}$ increased, more negatively charged surface was available thereby facilitating greater 
dye removal.

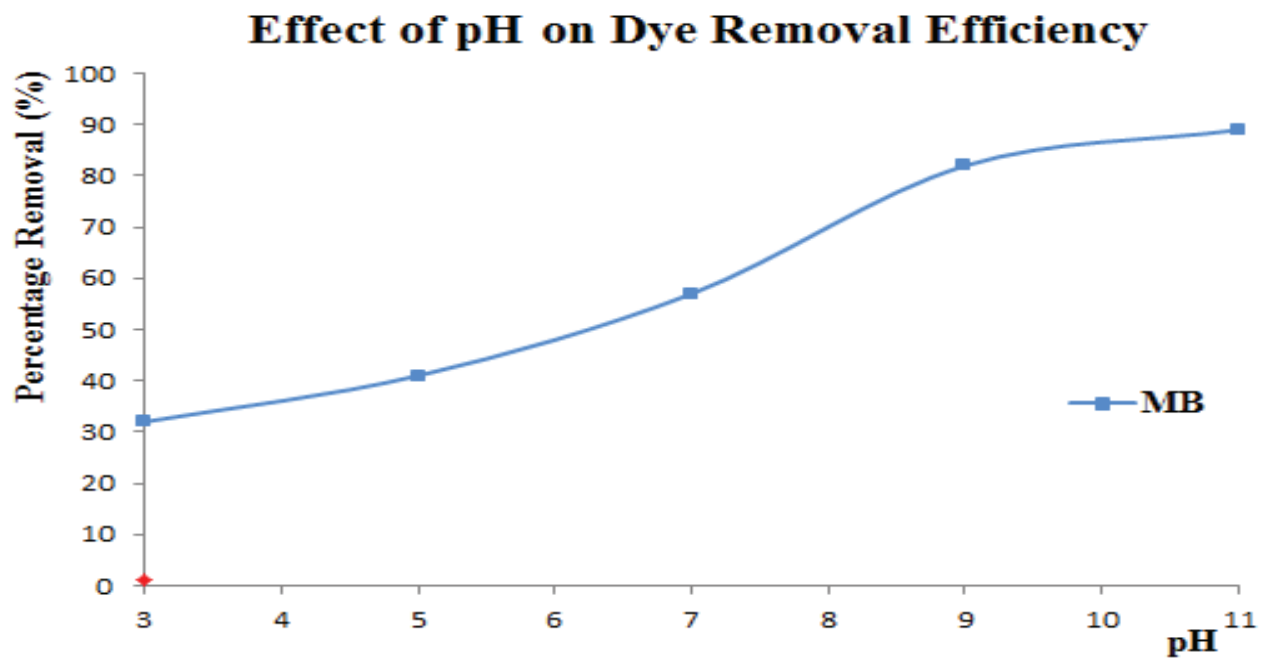

Figure 5: Effect of $\mathrm{pH}$ on the Percentage MB Dye Removal onto SOSAC at $1 \mathrm{~g}$ Carbon Dose, $30 \mathrm{mg} / \mathrm{L}$ Dye Concentration and 40 minutes Contact time.

\subsection{Effect of Temperature}

The effect of temperature on the percentage MB dye removal from solution with initial concentration of $20 \mathrm{mg} / \mathrm{L}$ at dye solution $\mathrm{pH}$ and varied temperatures of 30,40 and $50^{\circ} \mathrm{C}$ has been determined. It has been established that the percentage MB dye removal increased with increased in temperature and the result is presented in the Fig. 6. The increase in the percentage MB dye removal may be as a result of increase in the mobility of the large dye molecule with temperature. An increasing number of molecules may also acquire sufficient energy to undergo an interaction with active sites at the surface. Furthermore, increasing temperature may produce a swelling effect within the internal structure of the activated carbon enabling large dyes to penetrate further.

\section{Effect of Temperature on Dye Removal Efficiency}

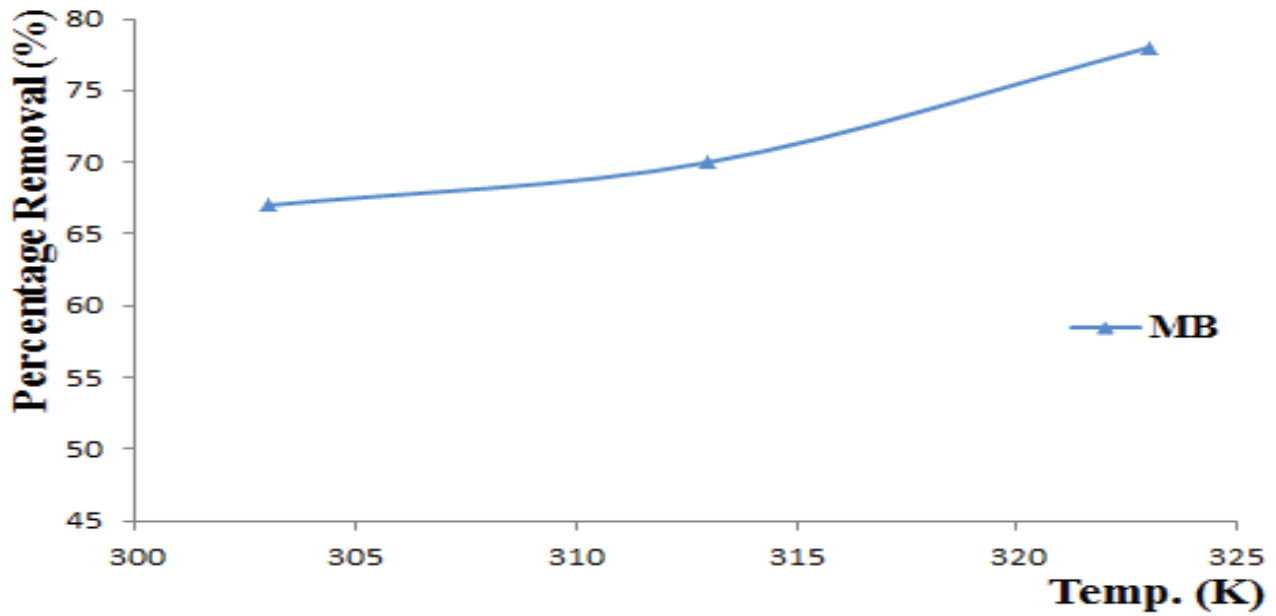

Figure 6: Effect of Temperature on the Percentage MB Dye Removal onto SOSAC at 0.5g Carbon Dosage, 20 $\mathrm{mg} / \mathrm{L}$ Dye Concentration and 40 minutes Contact time. 
3.6 Adsorption Isotherms

\section{Langmuir Adsorption Isotherm for MB}

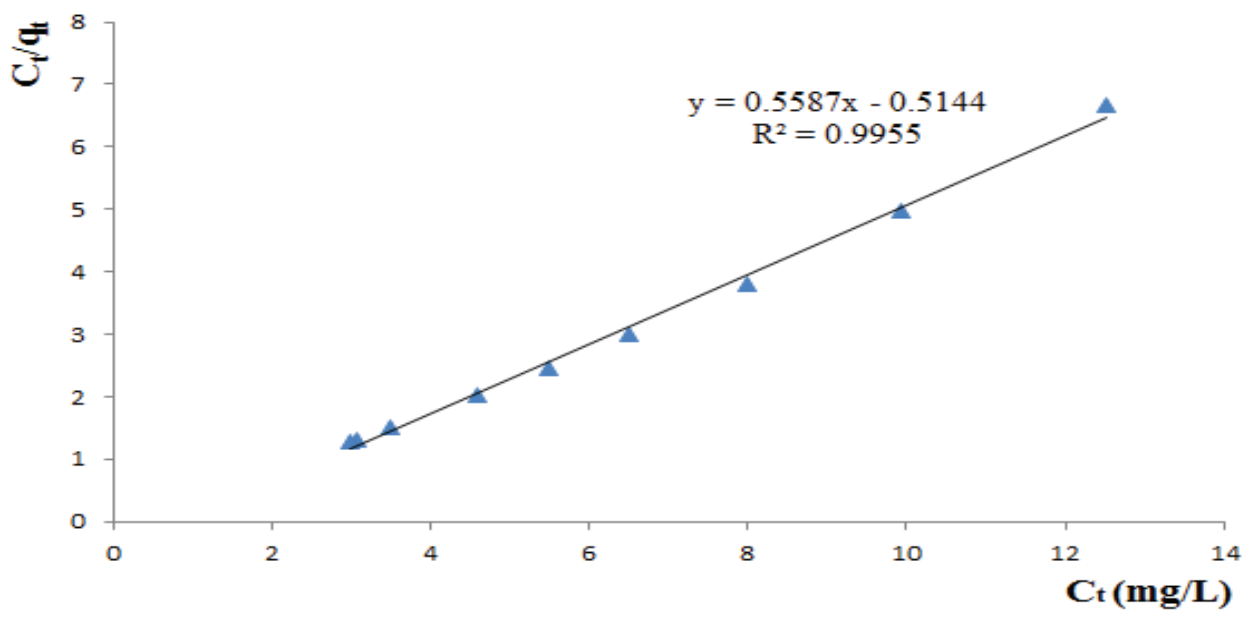

Figure 7: Langmuir Isotherm Plot for Adsorption of MB Dye onto SOSAC

Freundlich Adsorption Isotherm for MB

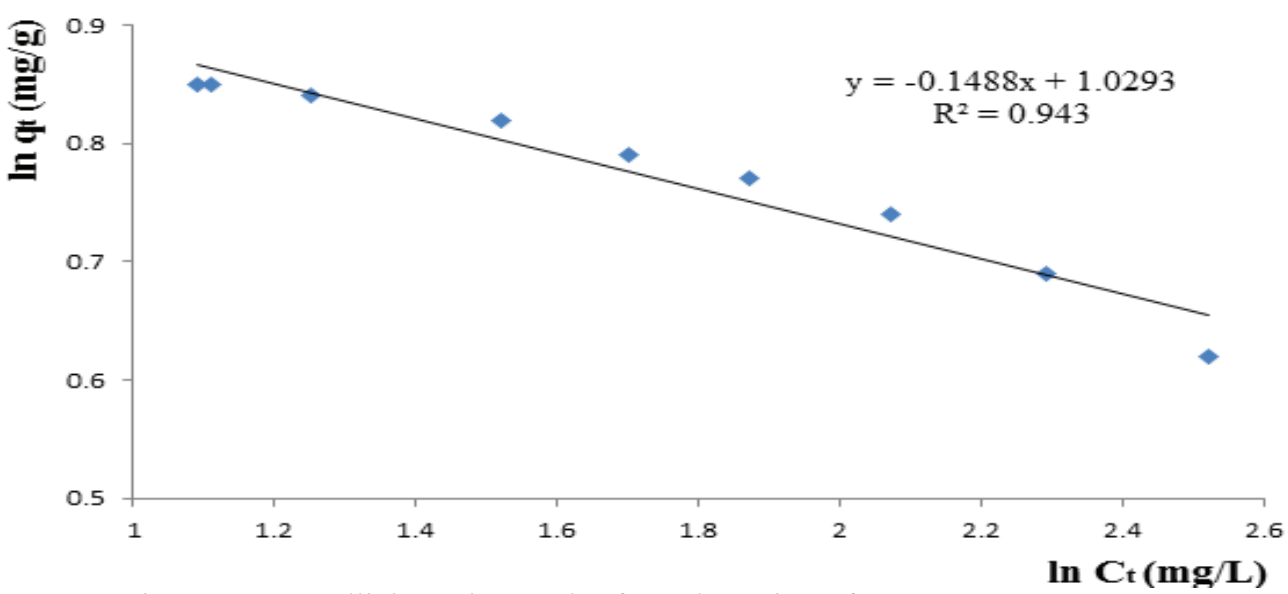

Figure 8: Freundlich Isotherm Plot for Adsorption of MB Dye onto SOSAC

\section{Temkin Adsorption Isotherm for MB}

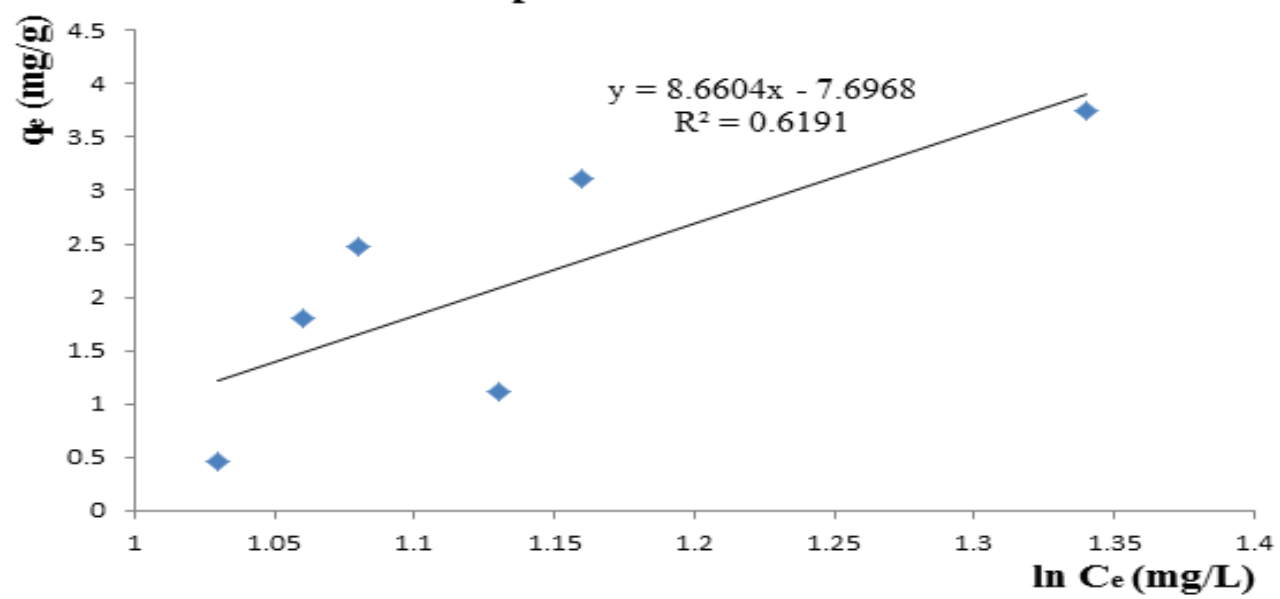

Figure 9: Temkin Isotherm Plot for Adsorption of MB Dye onto SOSAC

The plots of Langmuir, Freundlich and Temkin isotherm are shown from the Figs. 7-9 and the isotherm constants including the correlation coefficient $\left(\mathrm{R}^{2}\right)$ obtained are presented in the Table 1 . The results have clearly indicated that the adsorption of MB dye onto SOSAC fits well with the Langmuir model and hence, suggests 
monolayer and chemical adsorption.

Table 1: Langmuir, Freundlich and Temkin isotherm constants for the adsorption of MB dye onto SOSAC at $303 \mathrm{~K}$

\begin{tabular}{lll}
\hline Models & Parameters & Methylene Blue Dye \\
\hline Langmuir & $\mathrm{K}_{\mathrm{L}}\left(\mathrm{Lmg}^{-1}\right)$ & 1.09 \\
& $\mathrm{q}_{\mathrm{m}}(\mathrm{mg} / \mathrm{g})$ & 1.79 \\
& $\mathrm{R}_{\mathrm{L}}$ & 0.01 \\
$\mathrm{R}^{2}$ & 0.9955 \\
& & 2.80 \\
Freundlich & $\mathrm{K}_{\mathrm{f}}\left(\mathrm{Lg}^{-1}\right)$ & 0.148 \\
& $1 / \mathrm{n}$ & 6.72 \\
& $\mathrm{~N}$ & 0.9430 \\
& $\mathrm{R}^{2}$ & 2.43 \\
& $\mathrm{~K}_{\mathrm{T}}\left(\mathrm{L} \cdot \mathrm{mg}^{-1}\right)$ & 286.08 \\
& $\mathrm{~b}_{\mathrm{T}}\left(\mathrm{J} / \mathrm{mg}^{-1}\right.$ & 8.66 \\
$\mathrm{~B}_{1}\left(\mathrm{~J} \cdot \mathrm{mol}^{-1}\right)$ & 0.6191 \\
\hline
\end{tabular}

\subsection{Kinetic Studies}

\subsubsection{Pseudo First-order Kinetic Model}

In this study pseudo-first-order, pseudo-second-order, and intra-particle diffusion were applied to examine the controlling mechanism of dye adsorption from aqueous solution. Lagergren's first order rate equation is the earliest known to describe the adsorption rate based on adsorption capacity.

The linear form of Lagergren's first order equation is as in the eq. 8 (Lagergren, 1898):

$$
\ln \left(\mathrm{q}_{\mathrm{e}}-\mathrm{q}_{\mathrm{t}}\right)=\ln \mathrm{q}_{\mathrm{e}}-\mathrm{K}_{1} \mathrm{t}
$$

where; $\mathrm{q}_{\mathrm{e}}$ is the amount of dye adsorbed onto the adsorbent at equilibrium $(\mathrm{mg} / \mathrm{g}), \mathrm{q}_{\mathrm{t}}$ is the amount of dye adsorbed onto the adsorbent at any time $\mathrm{t}(\mathrm{mg} / \mathrm{g})$, and $\mathrm{K}_{1}\left(\mathrm{~min}^{-1}\right)$ is the rate constant of the pseudo first-order adsorption which can be calculated from the slope of the linear plot of $\ln \left(q \mathrm{q}-\mathrm{qt}\right.$ ) against $\mathrm{t}$ which gives $\mathrm{K}_{1}$ as slope and $\mathrm{q}_{\mathrm{e}}$ as intercept.

\section{Pseudo First-Order Kinetic Model for MB}

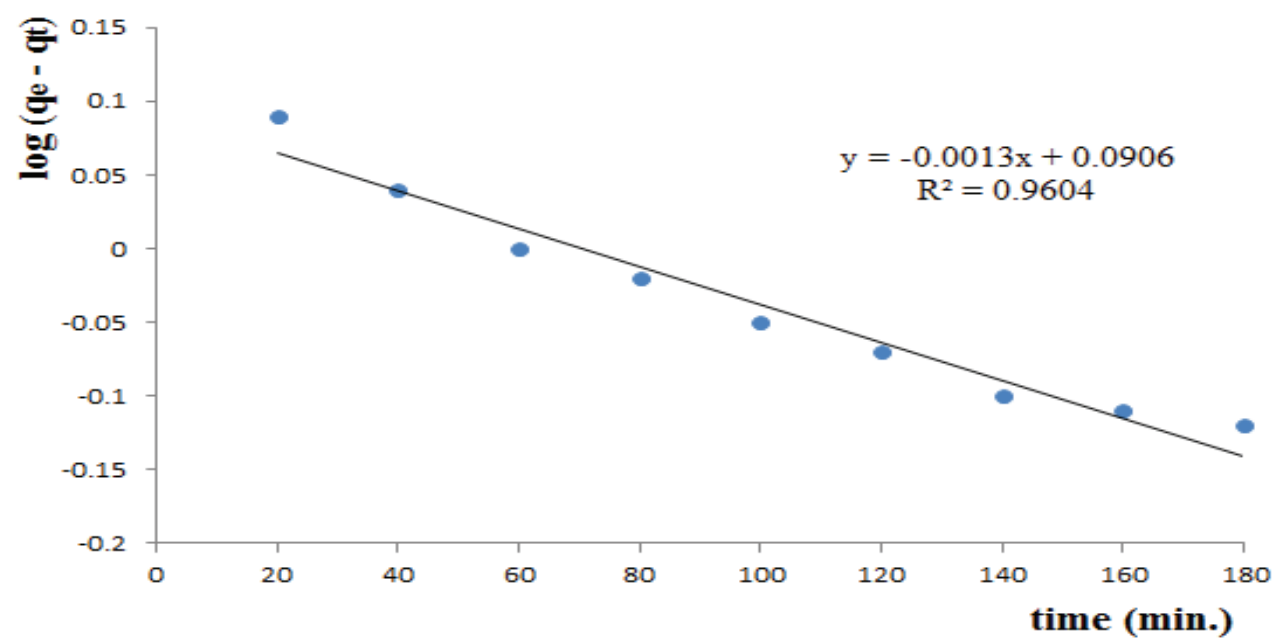

Figure 10: Pseudo-first Order Kinetics Model Plot for Adsorption of MB Dye onto SOSAC

\subsubsection{Pseudo Second-order Kinetic Model}

Ho et al., (2000) proposed a second order model for the sorption of divalent adsorbate ions or molecules onto peat particles based on the adsorption capacity of the adsorbents with the goal of differentiating the kinetics of a second-order rate expression based on the adsorbent concentration from models which are based on the solute concentration and represent a pseudo second-order rate expression.

The linear form of the pseudo second-order model can be as given by Ho et al., (2000):

$$
\mathrm{t} / \mathrm{q}_{\mathrm{t}}=1 / \mathrm{K}_{2} \mathrm{qe}^{2}+1 / \mathrm{q}_{\mathrm{e}}(\mathrm{t})
$$

where; $\mathrm{K}_{2}\left(\mathrm{gmg}^{-1} \mathrm{~min}^{-1}\right)$ is the rate constant of the pseudo-second-order adsorption, $\mathrm{q}_{\mathrm{e}}$ is the amount of dye adsorbed on the adsorbent at equilibrium $(\mathrm{mg} / \mathrm{g})$, and $\mathrm{q}_{\mathrm{t}}$ is the amount of dye adsorbed on the adsorbent at any time, $\mathrm{t}(\mathrm{mg} / \mathrm{g}) . \mathrm{K}_{2}\left(\mathrm{gmg}^{-1} \mathrm{~min}^{-1}\right)$ can be calculated from the slope and intercept of the plot of $\mathrm{t} / \mathrm{qt}$ against $\mathrm{t}$. 


\section{Pseudo-Second Order Kinetic Model for MB}

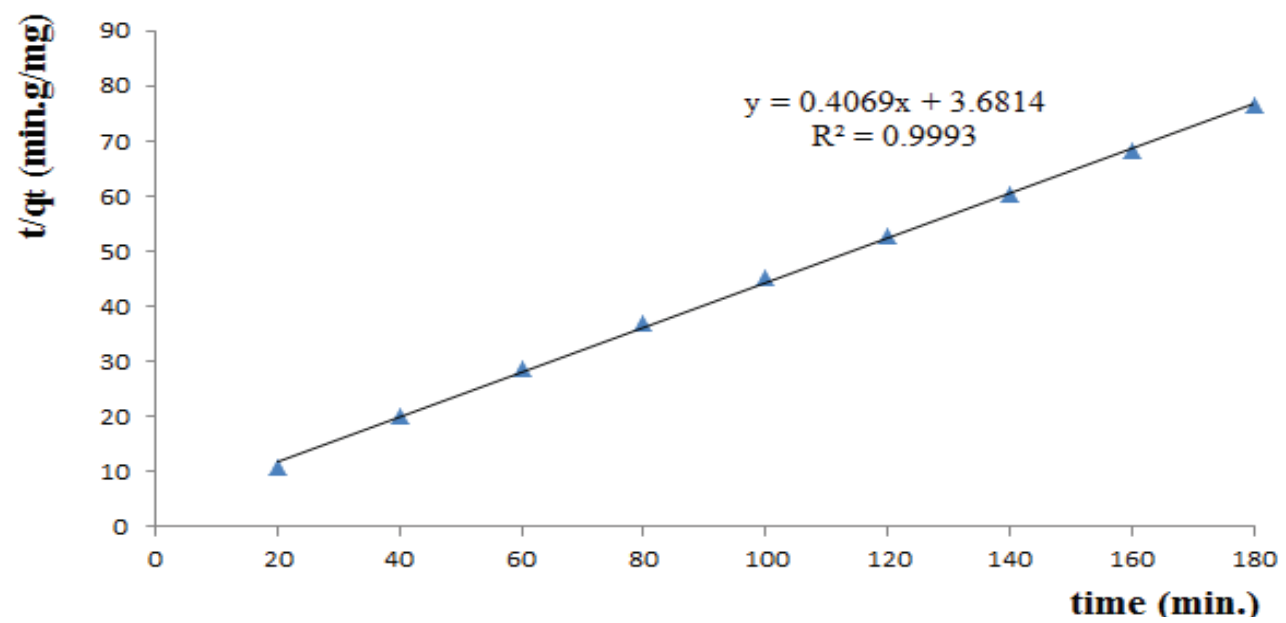

Figure 11: Pseudo Second-order Kinetics Model Plot for Adsorption of MB Dye onto SOSAC 3.7.3 Intra-particle Diffusion Model

The intra-particle diffusion model as put by Weber and Morris, (1962) is applied to describe the competitive adsorption involved between a liquid-solid system, which they believed that the adsorption of a fraction of solute onto the particle surface depends on; diffusivity of the solute within the particle and the particle radius.

The logarithmic form of the intra-particle diffusion model is given as eq. 10 (Weber and Morris, 1962):

$$
\log \mathrm{q}_{\mathrm{t}}=\log \mathrm{k}_{\mathrm{id}}+0.5 \log \mathrm{t}
$$

where; qt is the amount of dye adsorbed onto the adsorbent at time, $\mathrm{t}(\mathrm{mg} / \mathrm{g}), \mathrm{C}_{i d}$ is the intercept, and $\mathrm{K}_{i d}$ is the intra-particle diffusion rate constant $\left(\mathrm{mg} \cdot \mathrm{g}^{-1} \mathrm{~min}^{-1}\right)$.

The plot of $\log \mathrm{q}_{\mathrm{t}}$ against $0.5 \log \mathrm{t}$ should yield a straight line with a positive intercept for intra-particle diffusion controlled adsorption process. $\mathrm{k}_{\mathrm{id}}$ is determined from the intercept of the plot.

\section{Intra-Particle Diffusion Model for MB}

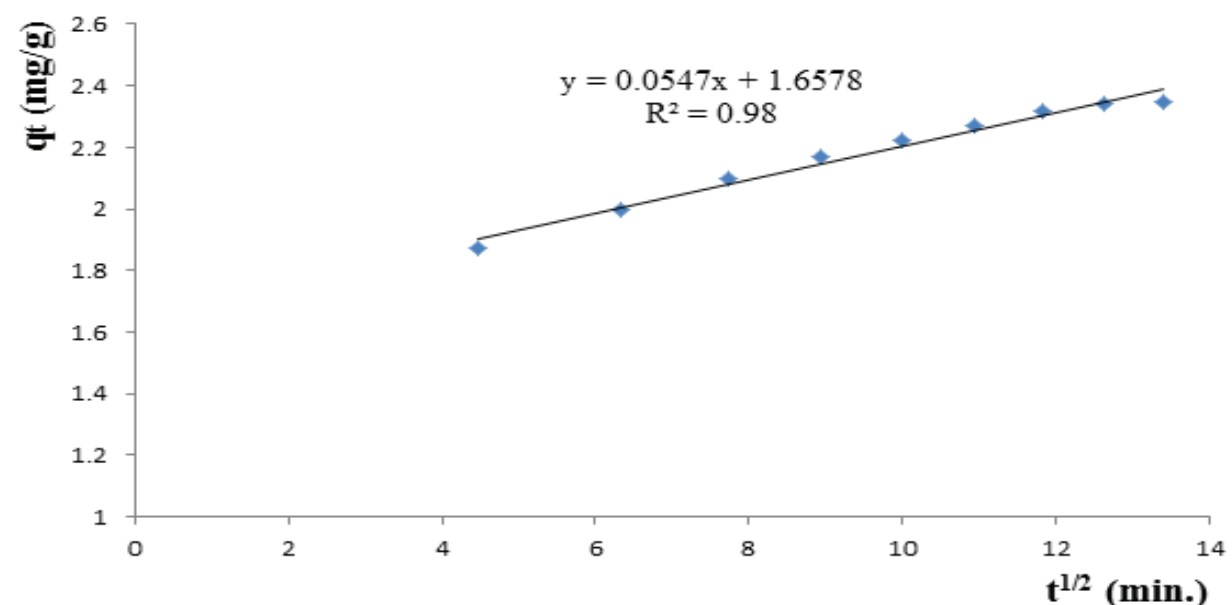

Figure 12: Intra-particle Diffusion Kinetics Model Plot for Adsorption of MB Dye onto SOSAC

Table 2: Constants from Kinetic Studies of MB Dye Adsorption onto SOSAC at 303K

\begin{tabular}{lll}
\hline Models & Parameters & Methylene Blue Dye \\
\hline Pseudo-first Order & $\mathrm{K}_{1}\left(\mathrm{~min}^{-1}\right)$ & $1.30 \times 10^{-3}$ \\
& $\mathrm{q}_{\mathrm{e}}(\mathrm{mg} / \mathrm{g})$ & 1.10 \\
& $\mathrm{R}_{2}$ & 0.9604 \\
Pseudo-second Order & $\mathrm{K}_{2}\left(\mathrm{~g} \cdot \mathrm{mg}^{-1} \mathrm{~min}^{-1}\right)$ & $4.49 \times 10^{-2}$ \\
& $\mathrm{q}_{\mathrm{e}}(\mathrm{mg} / \mathrm{g})$ & 2.46 \\
& $\mathrm{R}^{2}$ & 0.9993 \\
Intra-particle Diffusion & $\mathrm{K}_{\mathrm{id}}\left(\mathrm{mg} \cdot \mathrm{min}^{-1} \mathrm{~g}\right)$ & 0.055 \\
& $\mathrm{C}_{\mathrm{id}}(\mathrm{mg} / \mathrm{g})$ & 1.66 \\
& $\mathrm{R}^{2}$ & 0.9801 \\
\hline
\end{tabular}




\section{Conclusion}

Removal of MB dye from aqueous solutions by batch adsorption process using SOSAC has been experimentally studied and the following conclusions were reached;

1. The percentage of $\mathrm{MB}$ dye removed increases with increase in adsorbent dosage, contact time and temperature while, varied with $\mathrm{pH}$ of the dye solution. The higher the $\mathrm{pH}$, the greater the removals of $\mathrm{MB}$ dye by adsorption. The adsorption of these positively charged dye groups on the adsorbent surface is primarily influenced by the surface charge on the adsorbent which in turn is influenced by the solution $\mathrm{pH}$.

2. Optimum contact time for equilibrium was achieved at around $160 \mathrm{~min}$. It is basically due to saturation of the active sites which did not allow further adsorption. Optimum adsorbent dose for the dye is $1.5 \mathrm{~g} / 100 \mathrm{ml}$. It is obvious that with increasing amount the active sites for adsorption of the dyes increases which results in an increase in removal efficiency. The decrease in adsorption capacity with an increase in the adsorbent concentration could be ascribed to the fact that some of the adsorption sites remained saturated or not really involved during the process and agglomeration of activated carbons as a result all the surface area is not available for adsorption process. The optimum $\mathrm{pH}$ value and temperature were found to be at 11 and $50{ }^{\circ} \mathrm{C}$ respectively.

3. Langmuir was found among the three isotherm models tested to be the best that described the adsorption process while pseudo second-order when compared with pseudo first-order and intra-particle diffusion kinetic models was found to be the best suitable model that described the kinetic process of the adsorption.

\section{References}

Akpen, G.D., Nwaogazie, I.L. and Leton, T.G., (2011). Optimum Conditions for the Removal of Colour from Wastewater by Mango Seed Shell Based Activated Carbon. Indian Journal of Science and Technology, Vol. 4 (8). ISSN: 0974-6846: 890-894.

Ali, H., (2010). Biodegradation of synthetic dyes - A Review. Water Air Soil Pollution, Vol. 213, 251-273.

Freundlich, H.M.F., (1906). Over the Adsorption in Solution. Journal of Physical Chemistry, 57, 385-471.

Giwa, A., Nkeonye, P.O., Bello, K.A. and Kolawole, E.G., (2016). Synthesis of Acid Dyes Derived from Heterocyclic Diazo Component and Photocatalytic Degradation in $\mathrm{TiO}_{2}$ Suspension. Nigerian Journal of Scientific Research, 15(2), 197-204.

Gulumbe, N.S., Bukhari, M.M. and Abdulazeez, A.Y., (2019). Preparation and Characterization of Granular Activated Carbon from Senna Occidentalis Seeds. International Journal of Engineering and Modern Technology, ISSN 2504-8848 Vol. 5 (1), 1-11.

Gupta, V.K., Ali, I., Saleh, T.A., Nayak, A. and Agarwal, S., (2012). Chemical Treatment Technologies for Wastewater Recycling - An Overview. Royal Society of Chemistry (RSC) Advances, Vol. 2 (16), 63806388

Ho, Y.S, McKay, G., Wase, D.A.J and Forster, C.F., (2000). Study of the Sorption of Divalent Metal ions onto Peat. Adsorption Sci. Technol. 18, 639-650.

Jain, R., Bhargava, M. and Sharma, N., (2004). Electrochemical Studies on Pharmaceutical Azo Dyes: Tetrazine. Ind. Eng. Chem. Res., 42, 243.

Joshi, M., Bansal, R. and Purwar, R., (2004). Colour Removal from Textile Effluents. Indian Journal of Fibre \& Textile Research, Vol. 29. 239-259.

Lagergren, S., (1898). About the Theory of So-called Adsorption of Soluble Substance. Kunliga Svenska Velenskap-Sakademiens. Handlingar, 24 (4), 1-39.

Langmuir, I., (1916). The Constitution and Fundamental Properties of Solids and Liquids. Journal of American Chemical Society, 38, 2221-2295.

Langmuir, I., (1918). Adsorption of Gases on Plain Surfaces of Glass Mica Platinum. Journal of American Chemical Society, Vol. 40, 136-403.

Liu, B., Sheng, S., Hou, X., Wu, B., Yao, F. Ding, X. and Huang, L., (2018). Aerobic Biodegradation Characteristic of Different Water-Soluble Azo Dyes. Int. J. Environ. Res. Public Health, Vol. 15(35), 1-11.

Mohammed, M.A., Babagana, G. and Bitrus, K.H, (2015). Production and Characterization of Activated Carbon from Groundnut Shell Sourced In Maiduguri. Columban J. Life Sci., ISSN: 0972-0847, Vol. 17(1), 18-24.

Namasivayam, C. and Kavitha D., (2002). Removal of Congo Red from Water by Adsorption onto Activated Carbon from Coir Pith; An Agricultural Solid Waste. Dyes and Pigments, Vol. 54(1), 47-58.

Nandi, B.K. and Patel, S., (2013). Effects of Operational Parameters on the Removal of Brilliant Green Dye from Aqueous Solutions by Electrocoagulation. Arabian Journal of Chemistry, (2017) 10, 2961-2968.

Ng, C., Losso J.N., Marshall W.E. and Rao R.M., (2002). Freundlich Adsorption Isotherms of Agricultural Byproduct Based Powdered Activated Carbons in a Geosmin-Water System. Bioresource Technology, 85, $131-135$.

Oatley-Radcliffe, D.L., Walters, M., Ainscough, T.J., Williams, P.M., Mohammad, A. and Hilal, N., (2017). Nanofiltration Membranes and Processes: A Review of Research Trends over the Past Decade. Journal of 
Water Process Engineering, Vol. 19, 164-171.

Okoli, C.A., Onukwuli, O.D., Okey-Onyesolu, C.F. and Okoye, C.C., (2015). Adsorptive Removal of Dyes from Synthetic Wastewater Using Activated Carbon from Tamarind Seed. European Scientific Journal, ISSN: 1857-7881, Vol. 11(18), 190-220.

Omidi, K.Y, Mohammadi, M.J, Shegerd M., Sadeghi, S., Saeedi, S. and Basiri, H., (2017). Removal of Congo Red Dye from Aqueous Solutions by a Low-cost Adsorbent: Activated Carbon Prepared from Aloe Vera Leaves Shell. Environmental Health Engineering and Management Journal, 4(1): 29-35.

Sharifi, S.H., Archin, S. and Asadpour, G., (2018). Optimization of Process Parameters by Response Surface Methodology for Methylene Blue Removal Using Cellulose Dusts. Civil Engineering Journal, Vol. 4(3), $620-634$

Sharma, J. and Janveja, B., (2008). A Study on Removal of Congo Red Dye from the Effluents of Textile Industry Using Rice Husk Carbon Activated by Steam. Rasayan J. Chem. (RJC), Vol. 1(4), 936-942.

Tempkin, M.J. and Pyzhev, V., (1940). Recent Modification to Langmuir isotherms. Acta Physiochimica USSR $12,217-222$.

Vimonsesa, V., Lei, S., Jina, B., Chowd, C.W.K. and Saint, C., (2009). Kinetic Study and Equilibrium Isotherm Analysis of Congo Red Adsorption by Clay Materials. Chemical Engineering Journal, Vol. 148, (2-3), 354-364.

Weber, W. J. and Morris, J.C. (1962). Advances in Water Pollution Research: Removal of Biologically Resistant Pollutants from Waste Waters by Adsorption. Proceedings of International Conference on Water Pollution Symposium, Vol. 2, 231-266.

Wijannaro, S., Aroonsrimarakot, S., Thavipoke, P., Kumsopa, A. and Sangjan, S., (2013). Removal of Reactive Dyes from Textile Industrial Effluent by Ozonation Process. APCBEE Procedia, Vol. 5, 279-282.

Yakubu, M.K., Gumel, M.S. and Abdullahi, A.M., (2008). Use of Activated Carbon from Date Seeds to Treat Textile and Tannery Effluents. African Journal of Science and Technology (AJST) Science and Engineering Series, Vol. 9(1), 39-49. 